\title{
Weldability Studies and Parameter Optimization of AISI 904L Super Austenitic Stainless Steel Using Friction Welding
}

\author{
Karupanan Balamurugan ${ }^{\mathrm{a}}$,Mahendra Kumar Mishra ${ }^{\mathrm{b}}$,Paul Sathiya ${ }^{\mathrm{b}}$, Abdullah Naveen Sait ${ }^{* *}$
}

\author{
${ }^{a}$ Department of Mechanical Engineering, Periyar Maniammai University, \\ Thanjavur-613 403, Tamil Nadu, India \\ ${ }^{\mathrm{b}}$ Department of Production Engineering, National Institute of Technology, \\ Tiruchirappalli-620 015, Tamil Nadu, India \\ 'Department of Mechanical Engineering, Chendhuran College of Engineering and Technology, \\ Pudukkottai-622 507, Tamil Nadu, India
}

Received: October 24, 2013; Revised: March 24, 2014

\begin{abstract}
Welding input parameters play a very significant role in determining the quality of a weld joint. The quality of the joint can be defined in terms of mechanical properties, distortion and weld-bead geometry. Generally, all welding processes are employed with the aim of obtaining a welded joint with the desired characteristics. The purpose of this study is to propose a method to decide near optimal settings for the welding process parameters in friction welding of (AISI 904L) super austenitic stainless steel by using non conventional techniques and genetic algorithm (GA). Grey relational analysis and the desirability approach were applied to optimize the input parameters by considering multiple output variables simultaneously. An optimization method based on genetic algorithm was then applied to resolve the mathematical model and to select the optimum welding parameters. The main objective of this work is to determine the friction welding process parameters to maximize the fatigue life and minimize the width of the partial deformation zone (left \& right) and welding time. This study describes how to obtain near optimal welding conditions over a wide search space by conducting relatively a smaller number of experiments. The optimized values obtained through these evolutionary computational techniques were also compared with experimental results. ANOVA analysis was carried out to identify the significant factors affecting fatigue strength, welding time and partially deformed zone and to validate the optimized parameters.
\end{abstract}

Keywords: genetic algorithm, grey relational analysis, desirability approach, fatigue life, partially deformed zone (PDZ)

\section{Introduction}

Friction welding has great potentials in the field of aerospace and in other industrial applications specially in the production of steering shaft, tulip shaft, aluminum guide roller, track roller gear coupling body, flange gear and engine valve in automobile industry. In friction welding process, heat is generated by conversion of mechanical energy into thermal energy at the interfaces of the components during rotation under pressure without any energy from environment ${ }^{1-3}$. In continuous-drive method, one of the components is rotated at a constant speed (s), while the other is pushed toward the rotated part by a sliding action under a predetermined pressure - friction pressure. Friction pressure is applied for a certain friction time. Then, the drive is released and the rotary component is quickly stopped while the axial pressure is being increased to a higher predetermined upset pressure for a predetermined upset time ${ }^{4}$. This study concerns with the continuous-drive friction welding of (AISI 904L) super austenitic stainless steel. Super austenitic stainless steel is the preferred material for high corrosion resistance applications. This steel bridges

*e-mail: naveensait@yahoo.co.in the gap between relatively costlier austenitic stainless steel and expensive nickel base super alloys. The microstructure of super austenitic stainless steel (SASS) consists of a fully austenitic structure in the solution-quenched condition. To obtain good quality joint it is important to set up the proper welding process parameters. The welding process is a multi-input and multi-output process in which joints are closely associated with welding parameters. Therefore, identifying the suitable combinations of process input parameters to produce the desired output require many experiments making this process time consuming and costly. Therefore many studies had been carried out by various researchers on the process parameter optimization by using different conventional and non-conventional optimization techniques. Sathiya et al. ${ }^{5}$ investigated the effect of the laser welding input parameters (beam power, travel speed and focal position) based on three responses i.e. tensile strength, bead width and depth of penetration. The Taguchi approach was used as a statistical design of experiment (DOE) technique for optimizing the selected welding parameters. Grey relational analysis and the 
desirability approach were employed to optimize the input parameters by considering multiple output variables simultaneously. Optimization of laser welding by these two methods found suitable and successful for determining welding parameters. Confirmation experiments were also conducted for both of the analyses to validate the optimized parameters. Benyounis et al. ${ }^{6}$ applied design of experiment (DOE), evolutionary algorithms and computational network techniques to develop a mathematical relationship between the welding process input parameters and the output variables of the weld joint in order to determine the welding input parameters that lead to the desired weld quality. These techniques revealed good results for finding out the optimal welding conditions. The study by Sathiya et al. ${ }^{7}$ exposed an overall idea of the optimization of friction welding parameters using different techniques. Correia et al. ${ }^{8}$ proposed a method to decide near-optimal settings of a GMAW welding process. Near-best values of three control variables (welding voltage, wire feed rate and welding speed) based on four quality responses (deposition efficiency, bead width, depth of penetration and reinforcement), inside a previous delimited experimental region were chosen. The search for the near-optimal setting was carried out step by step, using genetic algorithm. The proposed GA manages to locate near optimum conditions, with a relatively small number of experiments. Vidyut Dey et al. ${ }^{9}$ developed a model to minimize the weldment area, after satisfying the condition of maximum bead penetration. Bead-on-plate weld runs were performed at an electron beam welding setup. Experiments were carried out as per central composite design and regression analysis was done to determine inputoutput relationships of the process. A binary-coded Genetic Algorithm with a penalty term was used to solve the said problem. The Genetic Algorithm was able to reach near the globally optimal solution. Paventhan et al. ${ }^{10}$ developed an empirical relationship to predict the tensile strength of friction welded AISI 1040 grade medium carbon steel and AISI 304 austenitic stainless steel, incorporating the process parameters such as friction pressure, forging pressure, friction time and forging time, which have great influence on strength of the joints. Response surface methodology was applied to optimize the friction welding process parameters to attain maximum tensile strength of the joint. There have been many studies related to modeling and optimization of different welding processes and other manufacturing processes. Some of these studies ${ }^{7,11,12}$ considered only a single output as the response, and mathematical model was developed which can accurately predict the output for a particular combination of input parameters. This modeling was done either based on response surface methodology or intelligent methods like artificial neural network. Even though some researchers ${ }^{13,14}$ have considered multi objective problems, they have followed a conventional approach in which the mathematical models were developed for each objective separately, and these models were combined into a single model. Abdullah et al. ${ }^{15}$ have discussed the different approaches in multi objective optimization using genetic algorithm (GA).

However, optimization of friction welding parameters by considering input variables i.e rotational speed (S), friction pressure (FP), upsetting pressure (UP), and burn of length (BOL) of 904 L Super Austenitic Stainless Steel (SASS) is not yet established. The main objective of this research work is to determine the near optimal welding process parameters using grey relational analysis, desirability analysis and genetic algorithm by considering multiple output parameters i.e. maximize the fatigue strength, minimize the welding time and partially deformed zone simultaneously.

\section{Experimental Details}

\subsection{Friction welding}

In the continuous drive friction welding process, one of the parts was held stationary while the other was rotated at a constant speed (n). The two parts were brought together under axial pressure $\left(\mathrm{P}_{1}\right)$ for certain friction time $\left(\mathrm{t}_{1}\right)$. Then the clutch was separated from the drive, and the rotary component was brought to stop within the braking time $\left(\mathrm{t}_{2}\right)$ while the axial pressure on the stationary part was increased to a higher forging pressure $\left(\mathrm{P}_{2}\right)$ for predetermined upset time $\left(\mathrm{t}_{4}\right)$. Schematic diagram of the continuous drive friction welding weld cycle is presented in Figure 1.

Friction welding of specimens was carried out using a continuous drive friction welding machine (ETA, Bangalore) with a maximum 60 tonnes capacity. The welding machine used for the experiments is shown in Figure 2. The machine has an advantage of adjusting the burn-off length, unlike other friction welding machines where the burn-off length is an output parameter. The friction welding time was obtained as an output. The material used for the study was AISI904L super austenitic stainless steel. The chemical composition of the material is shown in Table 1.

In this study, the experiments were conducted based on Taguchi L-18 orthogonal array ${ }^{16}$. The frictional power, burn off length, upset power and rotational speed were the input parameters with three levels each. The selected welding parameters and their levels are listed in Table 2. For each experimental test condition two trials were performed. The average of the two trials was considered as the output of a test condition, in order to ensure the repeatability of the test result. The welded specimens are shown in Figure 3.

The welding time was recorded from the machine for both the specimens and the average was taken. Using one out of the two sets of specimens, the macrograph was prepared. The weld profiles were prepared by machining process, and cut into a cross section of $10 \times 10 \mathrm{~mm}$ and polished with suitable abrasive and diamond paste. Weld samples were etched with $10 \%$ oxalic acid, an electrolyte, to state and increase the contrast of the fusion zone with the base metal. The macrograph of etched samples are shown in Figure 4a-d.

The left partially deformed zone (L.PDZ) and right partially deformed zone (R.PDZ) were measured.

\subsection{Fatigue test}

The fatigue test experiments were carried out under uniaxial tensile loading condition using servo hydraulic fatigue testing machine (Make: INSTRON, UK; Model: 8801) under constant amplitude loading (at room temperature). The fatigue test procedures were followed 
Table 1. Chemical composition of the Base material (wt. \%).

\begin{tabular}{cccccccccc}
\hline Elements & Si & Mn & P & S & Cr & Ni & Mo & C & \\
\hline Composition $(\%)$ & 0.374 & 1.522 & 0.018 & 0.004 & 19.893 & 25.557 & 4.124 & 0.018 & 1.650 \\
\hline
\end{tabular}

Table 2. Welding parameter levels.

\begin{tabular}{lcccccc}
\hline \multicolumn{1}{c}{ Parameters } & Level 1 & Level 2 & Level 3 & Level 4 & Level 5 & Level 6 \\
\hline Speed (rpm) & 1000 & 1200 & 1400 & 1600 & 1800 & 2000 \\
Friction pressure - FP (MPa) & 40 & 80 & 120 & - & - & - \\
Upset pressure - UP (MPa) & 125 & 150 & 175 & - & - & - \\
Burn-off Length - BOL (mm) & 2 & 4 & 6 & - & - & - \\
\hline
\end{tabular}

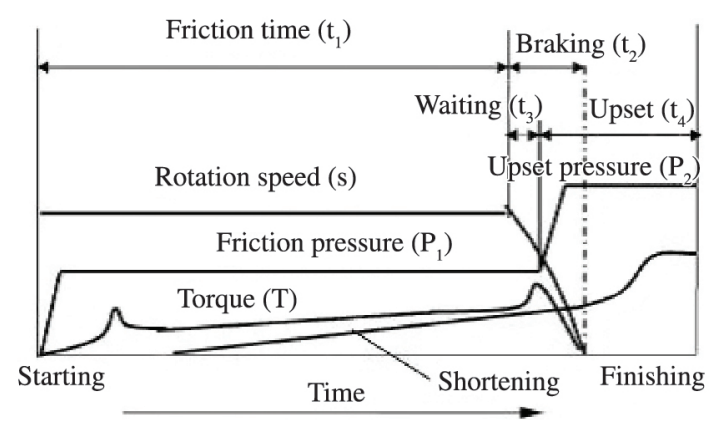

Figure 1. Friction welding weld cycle.

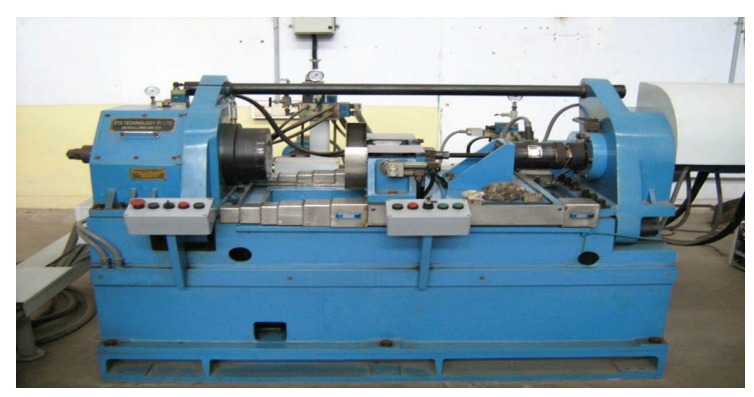

Figure 2. Friction welding machine.

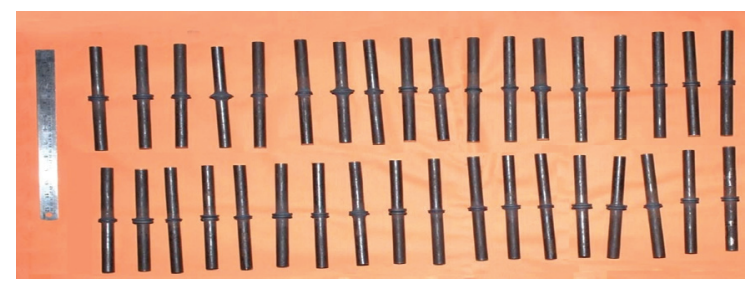

Figure 3. Friction Welded joints.

as per the ASTM E647-04 standard. The fatigue tested specimens are shown in Figure 5. The experimental data is tabulated in Table 3.

\section{Methodologies and Implementations}

\subsection{Grey relational analysis}

Deng $^{17}$ first proposed grey relational analysis in 1982 to fulfill the crucial mathematical criteria for dealing with poor, incomplete, and uncertain systems. This grey-based Taguchi technique has been widely used in different fields of engineering to solve multi-response optimization problems. In order to apply the grey-based Taguchi method for multi-response optimization, the following seven steps were followed:

Step 1: S/N ratio for the corresponding responses was calculated using the following formula:

(i) Larger-the-better:

$\mathrm{S} / \mathrm{N}$ ratio $(\eta)=-10 \log _{10}\left(\frac{1}{n} \sum_{i=1}^{n} \frac{1}{y_{i j}^{2}}\right)$

Where $\mathrm{n}=$ number of replications $\mathrm{y}_{\mathrm{ij}}=$ observed response value where $i=1,2, \ldots . . n ; j=1,2 \ldots k$

This was applied for the problem where maximization of the quality characteristic of interest was sought. This was referred as the larger-the-better type problem.

(ii) Smaller - the - better:

$\mathrm{S} / \mathrm{N}$ ratio $(\eta)=-10 \log _{10}\left(\frac{1}{n} \sum_{i=1}^{n} y_{i j}^{2}\right)$

This was termed as the smaller-the-better type problem where minimization of the characteristic was intended.

The $\mathrm{S} / \mathrm{N}$ ratios for a given response like fatigue strength (larger-the-better) and welding time, partially deformed zone (left \& right) (smaller-the-better) were calculated by using Equations 1 and 2, respectively. The computed $\mathrm{S} / \mathrm{N}$ ratios for each quality characteristic are shown in Table 4

Step 2: Normalization is a transformation performed on a single data input to distribute the data evenly and scale it in to an acceptable range for further analysis. Therefore, the normalization of original sequence of these four responses was done. As fatigue life follows Larger - the - better criterion (LB) normalization was done by Equation " 1 ".

$y_{i} *(k)=\frac{y i(k)-\min y i(k)}{\max y i(k)-\min y i(k)}$

Where $\mathrm{y}_{\mathrm{i}}^{*}(k)$ is the normalized data, i.e. after grey relational generation, $y_{i}(k)$ is the $k^{\text {th }}$ response of the $i^{\text {th }}$ experiment, $\min y_{i}(k)$ is the smallest value of $y_{i}(k)$ for the $k^{\text {th }}$ response, and max $y_{i}(k)$ is the largest value of $y_{i}(k)$ for the $k^{\text {th }}$ response.

Welding time and partially deformed zone (left \& right) follows the smaller - the - better (SB) criterion. 


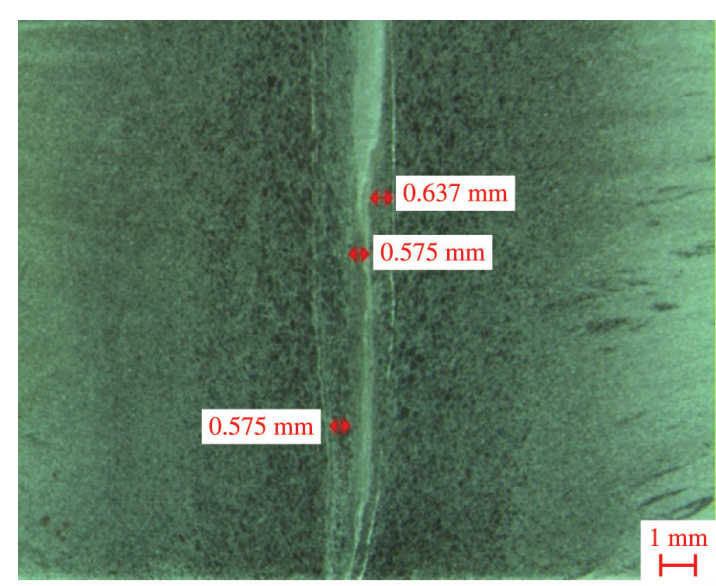

(a)

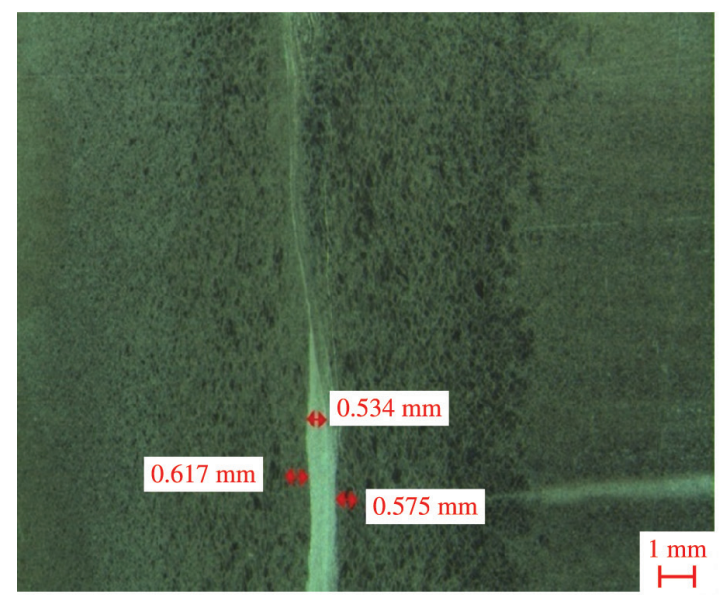

(c)

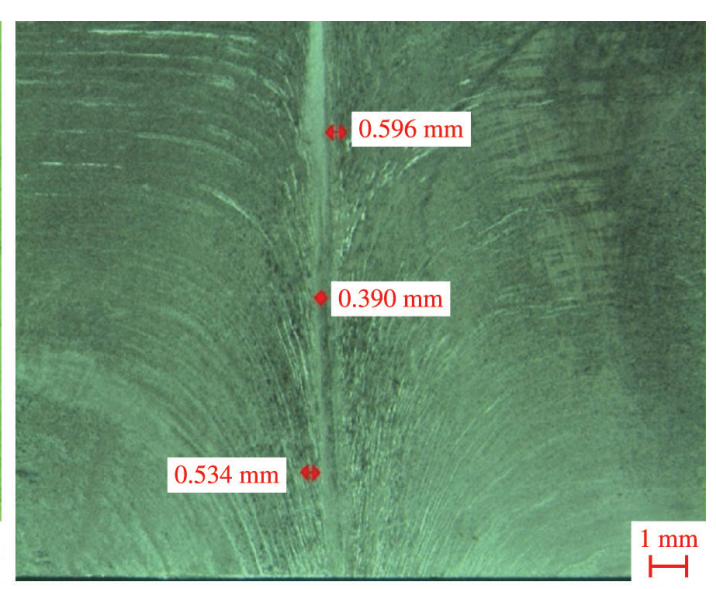

(b)

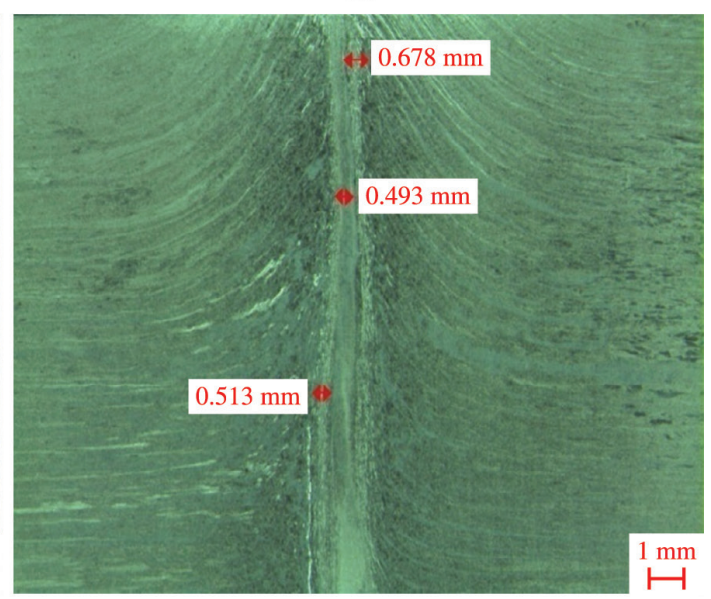

(d)

Figure 4. Macrograph of the welded joint.

Table 3. Experimental results.

\begin{tabular}{ccccccccc}
\hline Exp. No. & $\begin{array}{c}\text { Rotational } \\
\text { speed (rpm) }\end{array}$ & $\begin{array}{c}\text { Friction } \\
\text { pressure } \\
\text { (MPa) }\end{array}$ & $\begin{array}{c}\text { Upsetting } \\
\text { pressure } \\
(\mathbf{M P a})\end{array}$ & $\begin{array}{c}\text { Burn-off } \\
\text { length }(\mathbf{m m})\end{array}$ & $\begin{array}{c}\text { Welding } \\
\text { time }(\mathbf{s})\end{array}$ & $\begin{array}{c}\text { L.PDZ } \\
(\mathbf{m m})\end{array}$ & $\begin{array}{c}\text { R.PDZ } \\
(\mathbf{m m})\end{array}$ & $\begin{array}{c}\text { Fatigue } \\
\text { life }(\mathbf{n o .} \text { of } \\
\text { cycles })\end{array}$ \\
\hline $\mathbf{1}$ & 1000 & 40 & 125 & 2 & 62.78 & 0.575 & 0.637 & 135000 \\
$\mathbf{2}$ & 1000 & 80 & 150 & 4 & 33.5 & 0.534 & 0.596 & 184000 \\
$\mathbf{3}$ & 1000 & 120 & 175 & 6 & 17.25 & 0.308 & 0.452 & 300000 \\
$\mathbf{4}$ & 1200 & 40 & 125 & 4 & 196.43 & 0.658 & 1.006 & 175000 \\
$\mathbf{5}$ & 1200 & 80 & 150 & 6 & 36.64 & 0.493 & 0.411 & 235000 \\
$\mathbf{6}$ & 1200 & 120 & 175 & 2 & 15.63 & 0.431 & 0.575 & 325000 \\
$\mathbf{7}$ & 1400 & 40 & 150 & 2 & 128.63 & 0.617 & 0.575 & 200000 \\
$\mathbf{8}$ & 1400 & 80 & 175 & 4 & 24.47 & 0.658 & 0.678 & 302000 \\
$\mathbf{9}$ & 1400 & 120 & 125 & 6 & 20.5 & 0.78 & 0.76 & 250000 \\
$\mathbf{1 0}$ & 1600 & 40 & 175 & 6 & 81.05 & 0.596 & 0.678 & 195000 \\
$\mathbf{1 1}$ & 1600 & 80 & 125 & 2 & 24.41 & 0.513 & 0.678 & 172000 \\
$\mathbf{1 2}$ & 1600 & 120 & 150 & 4 & 15.02 & 0.514 & 0.596 & 155000 \\
$\mathbf{1 3}$ & 1800 & 40 & 150 & 6 & 119.17 & 0.534 & 0.699 & 220000 \\
$\mathbf{1 4}$ & 1800 & 80 & 175 & 2 & 35.64 & 0.37 & 0.493 & 240000 \\
$\mathbf{1 5}$ & 1800 & 120 & 125 & 4 & 17 & 0.534 & 0.555 & 185000 \\
$\mathbf{1 6}$ & 2000 & 40 & 175 & 4 & 209.07 & 0.493 & 0.431 & 310000 \\
$\mathbf{1 7}$ & 2000 & 80 & 125 & 6 & 31.89 & 0.555 & 0.596 & 275000 \\
$\mathbf{1 8}$ & 2000 & 120 & 150 & 2 & 20.52 & 0.555 & 0.699 & 290000 \\
\hline
\end{tabular}


Accordingly, the normalization of these responses was done using Equation "4".

$y_{i} *(k)=\frac{\max y i(k)-\min y i(k)}{\max y i(k)-\min y i(k)}$

The $\mathrm{S} / \mathrm{N}$ ratio values were normalized by using Equations 3 and 4 and calculated normalized values are presented in the same Table 4.

Step 3: The grey relational coefficient was calculated as

$\varepsilon_{i}(k)=\frac{\Delta \min +\varpi \Delta \max }{\Delta 0 i(k)+\varpi \Delta \max }$

where the grey relational coefficient of the $i^{\text {th }}$ experiment for the $k^{\text {th }}$ response is $\Delta_{o i}(k)=\left\|y^{*}(k)-y^{*}{ }_{i}(k)\right\|$, i.e. , absolute of the difference between $y^{*}(k)$ and $y^{*}{ }_{i}(k), y^{*}{ }_{o}(k)$ is the ideal or reference sequence, $\Delta_{\max }=\max _{\mathrm{i}} \max _{\mathrm{k}}\left\|y^{*}(k)-y^{*}{ }_{i}(k)\right\|$ is the largest value of $\Delta_{o i}$, and $\Delta_{\min }=\max _{\mathrm{i}} \max _{\mathrm{k}}\left\|y^{*}(k)-y^{*}{ }_{i}(k)\right\|$ is the smallest value of $\Delta_{o i}$, and $\omega(0 \leq \omega \leq 1)$ is the distinguish coefficient.

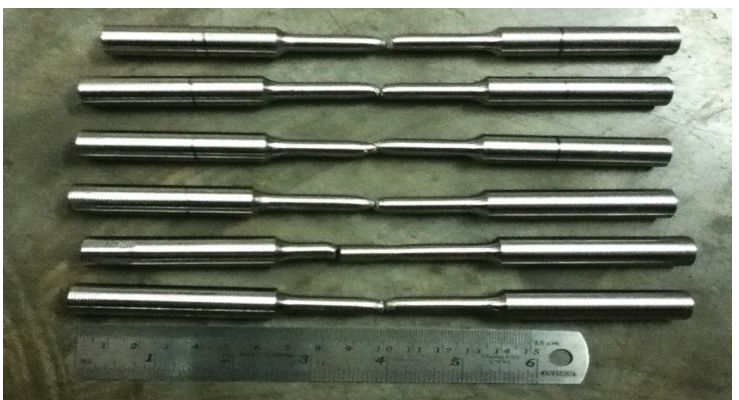

Figure 5. Fatigue tested specimens.
From the data in Table 4, the grey relational co-efficient for the normalized $\mathrm{S} / \mathrm{N}$ ratio values was calculated by using Equation 5. The value for $\xi \Delta \max$ is taken as $0.6,0.2,0.1$ and 0.1 for fatigue strength, welding time, partially deformed zone left and right respectively in Equation 5. The results are given in Table 5

Step 4: The grey relational grade $\left(\Gamma_{\mathrm{i}}\right)$ was calculated by averaging the grey relational coefficients corresponding to each experiment.

$\Gamma i={ }^{-1} \sum_{=1}^{Q} i(k)$

Where, $\mathrm{Q}$ is the total number of responses. A high grey relational grade corresponds to intense relational degree between the given sequence and the reference sequence. The reference sequence, $\mathrm{y}^{*}{ }_{\mathrm{o}}(k)$, represented the best process sequence; therefore, higher grey relational grade meant that the corresponding parameter combination was closer to the optimal setting. The grey relational grade can be computed by Equation 6. Finally, the grades were considered for optimizing the multi response parameter design problem. The results are given in the Table 5 .

Step 5: The optimal factor and its level combination were determined. The higher grey relational grade implied the better product quality; therefore, on the basis of grey relational grade, the factor effect can be estimated and the optimal level for each controllable factor can also be determined. For example, to estimate the effect of factor ' $i$ ', we calculated the average of grey grade values (AGV) for each level ' $j$ ', denoted as $A V_{i j}$, and then the effect, $E_{i}$ is defined as:

$E i=\max (A G V i j)-\min (A G V i j)$

If the factor $\mathrm{i}$ is controllable, the best level $\mathrm{j}^{*}$, is determined by

Table 4. S/N ratio values and normalized $\mathrm{S} / \mathrm{N}$ ratio values.

\begin{tabular}{ccccccccc}
\hline \multirow{2}{*}{$\begin{array}{c}\text { Trail } \\
\text { No. }\end{array}$} & \multicolumn{5}{c}{ S/N ratios } & \multicolumn{4}{c}{ Normalized values of S/N ratios $\mathbf{y}_{\mathbf{i}} *(\mathbf{k})$} \\
\cline { 2 - 9 } & W. Time & L.PDZ & R.PDZ & Fatigue life & W. Time & L.PDZ & R.PDZ & Fatigue life \\
\hline 1 & -35.9564 & 4.806643 & 3.917211 & 102.6067 & 0.5431440 & 0.6718405 & 0.4895038 & 0 \\
2 & -30.5009 & 5.449175 & 4.495075 & 105.2964 & 0.3046242 & 0.5922294 & 0.4151817 & 0.3524681 \\
3 & -24.7358 & 10.22899 & 6.897231 & 109.5424 & 0.0525691 & 0 & 0.0344138 & 0.9088923 \\
4 & -45.8642 & 3.635482 & -0.05196 & 104.8608 & 0.9763174 & 0.8169500 & 1 & 0.2953857 \\
5 & -31.2791 & 6.143062 & 7.723164 & 107.4214 & 0.3386483 & 0.5062552 & 0 & 0.6309379 \\
6 & -23.8792 & 7.310455 & 4.806643 & 110.2377 & 0.0151178 & 0.3616126 & 0.3751092 & 1 \\
7 & -42.1868 & 4.194297 & 4.806643 & 106.0206 & 0.8155426 & 0.7477116 & 0.3751092 & 0.4473762 \\
8 & -27.7727 & 3.635482 & 3.375406 & 109.6001 & 0.1853445 & 0.8169500 & 0.5591882 & 0.9164554 \\
9 & -26.2351 & 2.158108 & 2.383728 & 107.9588 & 0.1181194 & 1 & 0.6867332 & 0.7013669 \\
10 & -38.1751 & 4.495075 & 3.375406 & 105.8007 & 0.6401444 & 0.7104445 & 0.5591882 & 0.4185585 \\
11 & -27.7514 & 5.797653 & 3.375406 & 104.7106 & 0.1844122 & 0.1846389 & 0.5591882 & 0.2757038 \\
12 & -23.5334 & 5.780738 & 4.495075 & 103.8066 & 0 & 0.5511480 & 0.4151817 & 0.1572480 \\
13 & -41.5233 & 5.449175 & 3.110456 & 106.8485 & 0.7865336 & 0.5922294 & 0.5932648 & 0.5558620 \\
14 & -31.0388 & 8.635966 & 6.143062 & 107.6042 & 0.3281397 & 0.1973788 & 0.2032253 & 0.6549017 \\
15 & -24.609 & 5.449175 & 5.11414 & 105.3434 & 0.0470251 & 0.5922294 & 0.3355604 & 0.3586374 \\
16 & -46.4058 & 6.143062 & 7.310455 & 109.8272 & 1 & 0.5062552 & 0.0530807 & 0.9462149 \\
17 & -30.0731 & 5.11414 & 4.495075 & 108.7867 & 0.2859202 & 0.6337409 & 0.4151817 & 0.8098526 \\
18 & -26.2435 & 5.11414 & 3.110456 & 109.248 & 0.1184897 & 0.6337409 & 0.5932649 & 0.8703042 \\
\hline & & & & & & & & \\
\hline
\end{tabular}




$$
j^{*}=\max (A G V i j)
$$

From the value of grey relational grade in Table 5, by using Equations 7 and 8, the main effects are tabulated in Table 6 and the factor effects are plotted in Figure 6.

Step 5: ANOVA was performed for identifying the significant factors.

The main purpose of the analysis of variance (ANOVA) was to apply a statistical method to identify the effect of individual factors. Results from ANOVA would determine very clearly the impact of each factor on the process results. The Taguchi experimental method could not judge the effect of individual parameters on the entire process; thus, the percentage of contribution using ANOVA was used to compensate this effect. The total sum of the squared deviations $\mathrm{SS}_{\mathrm{T}}$ was decomposed into two sources: the sum of the squared deviations due to each process parameter and the sum of the squared error. The percentage contribution by each of the process parameter in the total sum of the squared deviations $\mathrm{SS}_{\mathrm{T}}$ can be used to evaluate the importance of the process parameter change on the performance characteristics. Usually, the change of the process parameter has a significant effect on the performance characteristic when the ' $F$ ' value is large.
The results of ANOVA are given in Table 7. From ANOVA, it is clear that rotational speed (50.44\%) influences more on welding followed by upsetting pressure $(25.38 \%)$, friction pressure (15.65\%), and burn-off length (1.84\%).

\subsection{Desirability approach}

The desirability function approach to optimize multiple equations simultaneously was originally proposed by Harrington. Essentially, the approach is to translate the functions to a common scale $(0,1)$, combine them using the geometric mean and optimize the overall metric. There are many statistical techniques like overlaying the contours plot for each response, constrained optimization problems and desirability approach for solving multiple response problems. The desirability method is recommended due to its simplicity, availability in the software, flexibility in weighting and giving importance for individual response. Solving such multiple response optimization problems using this technique involves using a technique for combining multiple responses into a dimensionless measure of performance called the overall desirability function. The desirability approach involves transforming each estimated response, $\mathrm{Yi}$, into a unit less utility bounded by $0<\mathrm{d}_{\mathrm{i}}<1$, where a higher ' $d_{i}$ ' value indicates that response value $\mathrm{Yi}$ is more desirable, if $\mathrm{di}=0$ this means a completely undesired

Table 5. Grey relational co-efficient and grey grade values.

\begin{tabular}{cccccc}
\hline \multirow{2}{*}{$\begin{array}{c}\text { Trail } \\
\text { No }\end{array}$} & \multicolumn{2}{c}{ Grey relational co-efficient } & \multirow{2}{*}{ Grey grade } \\
\cline { 2 - 4 } & W. Time & L.PDZ & R.PDZ & Fatigue life & 0.325632 \\
\hline 1 & 0.304481 & 0.233558 & 0.163801 & 0.375 & 0.36754 \\
2 & 0.22337 & 0.196939 & 0.146024 & 0.48095 & 0.574239 \\
3 & 0.174302 & 0.090909 & 0.093845 & 0.868171 & 0.590098 \\
4 & 0.894124 & 0.353294 & 1 & 0.459906 & 0.443865 \\
5 & 0.232193 & 0.168423 & 0.090909 & 0.619155 & 0.661097 \\
6 & 0.168793 & 0.13543 & 0.137952 & 1 & 0.458555 \\
7 & 0.520214 & 0.283858 & 0.137952 & 0.520551 & 0.619909 \\
8 & 0.197111 & 0.353294 & 0.184907 & 0.877777 & 0.561779 \\
9 & 0.184863 & 1 & 0.241974 & 0.667681 & 0.420321 \\
10 & 0.357235 & 0.256703 & 0.184907 & 0.507854 & 0.340644 \\
11 & 0.19693 & 0.109247 & 0.184907 & 0.453071 & 0.315679 \\
12 & 0.166667 & 0.182198 & 0.146024 & 0.415872 & 0.480953 \\
13 & 0.483715 & 0.196939 & 0.197342 & 0.574637 & 0.449022 \\
14 & 0.229395 & 0.110788 & 0.111511 & 0.634855 & 0.357472 \\
15 & 0.173464 & 0.196939 & 0.130815 & 0.48334 & 0.777034 \\
16 & 1 & 0.168423 & 0.095518 & 0.917733 & 0.535421 \\
17 & 0.218799 & 0.214473 & 0.146024 & 0.759352 & 0.571523 \\
18 & 0.184927 & 0.214473 & 0.197342 & 0.822261 & \\
\hline
\end{tabular}

Table 6. Main effects on grey grades.

\begin{tabular}{lccccccccc}
\hline \multicolumn{1}{c}{ Factor/ level } & $\mathbf{1}$ & $\mathbf{2}$ & $\mathbf{3}$ & $\mathbf{4}$ & $\mathbf{5}$ & $\mathbf{6}$ & Difference & $\begin{array}{c}\text { Rank } \\
\text { Optimum } \\
\text { Levels }\end{array}$ \\
\hline Speed & 0.42247 & 0.56502 & 0.54675 & 0.35888 & 0.42914 & $\mathbf{0 . 6 2 7 9}$ & 0.26911 & 1 & SPEED6 \\
Friction Pressure & $\mathbf{0 . 5 0 8 7 6}$ & 0.4594 & 0.50696 & - & - & - & 0.04936 & 3 & FB1 \\
Upsetting Pressure & 0.45184 & 0.43969 & $\mathbf{0 . 5 8 3 6 0}$ & - & - & - & 0.14391 & 2 & UP3 \\
Burn-off length & 0.46774 & $\mathbf{0 . 5 0 4 6 2}$ & 0.50276 & - & - & - & 0.03687 & 4 & BOL2 \\
\hline
\end{tabular}


response. In order to apply the desirability approach method for multi-response optimization, the following seven steps were followed:

Step 1: The individual desirability index $\left(\mathrm{d}_{\mathrm{i}}\right)$ for the corresponding responses was calculated using the following Equations 9 and 10. There were different forms of the desirability functions according to the response characteristics.

The Larger-the better

$d_{i}=\left\{\begin{array}{l}0, y_{j} \leq y_{\min } \\ \left(\frac{y_{j}-y_{\min }}{y_{\max }-y_{\min }}\right)^{r}, y_{\min } \leq y_{j} \leq y_{\max }, r \geq 0 \\ 1, y_{j} \geq y_{\min }\end{array}\right.$

The value of ' $y_{j}$ ' was expected to be the larger the better. When the ' $y$ ' exceeded a particular criteria value, which can be viewed as the requirement, the desirability value equaled to 1 ; if the ' $y$ ' was less than a particular criteria value, which was unacceptable, the desirability value equaled to 0 .

The Smaller-the better

$d_{i}=\left\{\begin{array}{l}1, y_{j} \leq y_{\min } \\ \left(\frac{y_{j}-y_{\max }}{y_{\min }-y_{\max }}\right)^{r}, y_{\min } \leq y_{j} \leq y_{\max }, r \geq 0 \\ 0, y_{j} \geq y_{\min }\end{array}\right.$

The value of ' $y_{j}$ ' was expected to be the smaller the better. When the ' $y$ ' was less than a particular criteria value, the desirability value equaled to 1 ; if the ' $y$ ' exceeds a particular criteria value, the desirability value equaled to 0 .

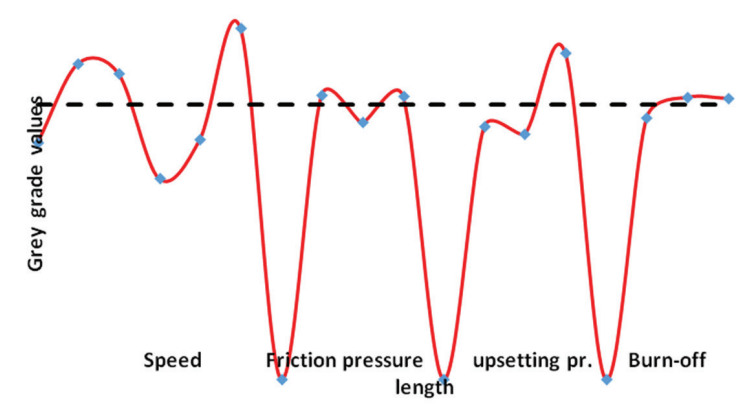

Figure 6. Factor effects on grade values.
The individual desirability $\left(\mathrm{d}_{\mathrm{i}}\right)$ was calculated for all the responses depending upon the type of quality characteristics. The main objectives of this work are minimization of welding time, width of the partially deformed zone (left \& right) and maximization of fatigue strength. According to this objective the responses were considered. The larger the better type and the smaller the better type were selected for this study. The values of computed individual desirability for each quality characteristics using the Equations 9 and 10 are presented in Table 8.

Step 2: The composite desirability $\left(\mathrm{d}_{\mathrm{G}}\right)$ was computed. The individual desirability index of all the responses can be combined to form a single value called composite desirability $\left(\mathrm{d}_{\mathrm{G}}\right)$ by the following Equation 11 .

$d_{G}=\sqrt[w]{\left(d_{1}{ }^{w 1} \times d_{2}{ }^{w 2} \ldots \ldots . . d_{i}{ }^{w i}\right)}$

The composite desirability values $\left(\mathrm{d}_{\mathrm{G}}\right)$ were calculated using equation 11 . The weightage for responses were based on assumption of fatigue strength (0.6), welding time (0.2) and Left partially deformed zone (0.1) and Right partially deformed zone (0.1). Finally, these values were considered for optimizing the multi-response parameter design problem and the calculated results are given in the Table 8 .

Step 3: The optimal parameter and its level combination were determined. The higher composite desirability value implied better product quality. Therefore, on the basis of the composite desirability $\left(\mathrm{d}_{\mathrm{G}}\right)$, the parameter effect and the optimum level for each controllable parameter were estimated. For examples, to estimate the effect of factor ' $i$ ', we calculated the composite desirability values (CDV) for each level ' $\mathrm{j}$ ', denoted as $\mathrm{CDV}_{\mathrm{ij}}$, and then the effect, $\mathrm{E}_{\mathrm{i}}$ is defined as:

$E_{i}=\max \left(C D V_{i j}\right)-\min \left(C D V_{i j}\right)$

If the factor $\mathrm{i}$ is controllable, the best level $\mathrm{j}^{*}$, is determined by

$j^{*}=\max _{j}\left(C D V_{i j}\right)$

From the value of composite desirability in Table 8, by using Equations 12 and 13, the main parameter effects are tabulated in Table 9 and the factor effects are plotted in Figure 7.

Step 4: ANOVA was performed for identifying the significant parameters. ANOVA established the relative significance of parameters. The calculated total sum of square values was used to measure the relative influence

Table 7. Results of ANOVA on grey grade.

\begin{tabular}{lcccccc}
\hline \multicolumn{1}{c}{ Factor } & Sum of Squares & $\begin{array}{c}\text { Degree of } \\
\text { freedom }\end{array}$ & Mean squares & FCAL & F-TEST & \% Contribution \\
\hline Speed & 0.14198 & 5 & 0.02840 & 9.05719 & 4.2565 & 50.44 \\
Friction pressure & 0.04405 & 2 & 0.02203 & 7.02514 & 4.2565 & 15.65 \\
Upsetting Pressure & 0.07144 & 2 & 0.03572 & 11.39339 & 4.2565 & 25.38 \\
Burn-off length & 0.00518 & 2 & 0.00259 & 0.82594 & 4.2565 & 1.84 \\
Error & 0.01881 & 6 & 0.00314 & & & 6.68 \\
Total & 0.28147 & 17 & & & & \\
\hline
\end{tabular}


Table 8. Desirability values and composite desirability values.

\begin{tabular}{cccccc}
\hline \multirow{2}{*}{ Trial No } & \multicolumn{2}{c}{ Individual desirability } & Composite \\
\cline { 2 - 4 } & Welding Time & Left PDZ & Right PDZ & Fatigue life & desirability \\
\hline 1 & 0.753878 & 0.434322 & 0.620168 & 0 & 0 \\
2 & 0.904767 & 0.521186 & 0.689076 & 0.257895 & 0.381832 \\
3 & 0.988508 & 1 & 0.931092 & 0.868421 & 0.904763 \\
4 & 0.065138 & 0.258475 & 0 & 0.210526 & 0 \\
5 & 0.888585 & 0.608051 & 1 & 0.526316 & 0.639752 \\
6 & 0.996856 & 0.739407 & 0.72437 & 1 & 0.909376 \\
7 & 0.414532 & 0.345339 & 0.72437 & 0.342105 & 0.405572 \\
8 & 0.951301 & 0.258475 & 0.551261 & 0.878947 & 0.71404 \\
9 & 0.97176 & 0 & 0.413445 & 0.605263 & 0 \\
10 & 0.659727 & 0.389831 & 0.551261 & 0.315789 & 0.388091 \\
11 & 0.95161 & 0.565678 & 0.551261 & 0.194737 & 0.312639 \\
12 & 1 & 0.563559 & 0.689076 & 0.105263 & 0.227046 \\
13 & 0.463283 & 0.521186 & 0.515966 & 0.447368 & 0.469037 \\
14 & 0.893739 & 0.868644 & 0.862185 & 0.552632 & 0.663112 \\
15 & 0.989796 & 0.521186 & 0.757983 & 0.263158 & 0.39748 \\
16 & 0 & 0.608051 & 0.966387 & 0.921053 & 0 \\
17 & 0.913064 & 0.476695 & 0.689076 & 0.736842 & 0.711135 \\
18 & 0.971657 & 0.476695 & 0.515966 & 0.815789 & 0.721092 \\
\hline
\end{tabular}

Table 9. Main effects on desirability analysis.

\begin{tabular}{lcccccccccc}
\hline \multicolumn{1}{c}{ Factor/level } & $\mathbf{1}$ & $\mathbf{2}$ & $\mathbf{3}$ & $\mathbf{4}$ & $\mathbf{5}$ & $\mathbf{6}$ & $\begin{array}{c}\text { Difference } \\
\text { Rank }\end{array}$ & $\begin{array}{c}\text { Optimum } \\
\text { Levels }\end{array}$ \\
\hline Speed & 0.42886 & $\mathbf{0 . 5 1 6 3 8}$ & 0.37320 & 0.10325 & 0.50987 & 0.47740 & 0.41312 & SPEED2 \\
Friction Pressure & 0.21045 & $\mathbf{0 . 5 7 0 4 2}$ & 0.52663 & - & - & - & 0.35997 & 2 \\
Upsetting Pressure & 0.23687 & 0.47405 & $\mathbf{0 . 5 9 6 5 6}$ & - & - & - & 0.35969 & 3 \\
Burn-off length & 0.50196 & 0.28673 & $\mathbf{0 . 5 1 8 8 0}$ & - & - & - & 0.23206 & 4 \\
\hline
\end{tabular}

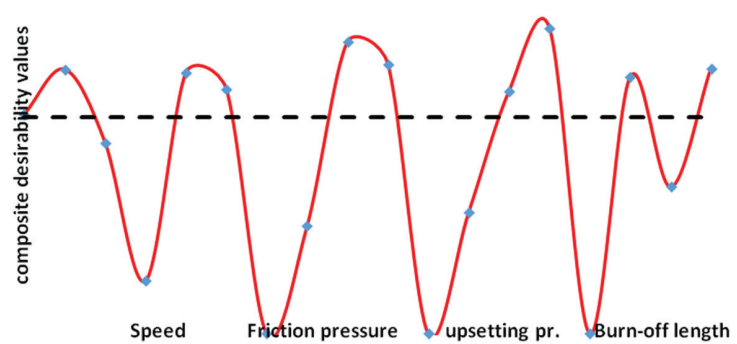

Figure 7. Factor effects on grade values.

of the parameters. Using the composite desirability value, ANOVA was formulated for identifying the significance of the individual factors.

The results of ANOVA are given in Table 10. From ANOVA, it was clear that rotational speed $(37.90 \%)$ influenced more on welding followed by upsetting pressure $(22.60 \%)$, friction pressure $(25.60 \%)$, and burn-off length $(6.94 \%)$.

\subsection{Genetic algorithm}

Genetic algorithms (GAs) are well known types of evolutionary computation methods and they have been adapted for large number of applications in different areas. The GAs differ from most optimization techniques because of their global searching from one population of solutions rather than from one single solution. It is a heuristic technique inspired by the natural biological evolutionary process comprising of proper selection of, crossover, mutation, etc. The evolution starts with a population of randomly generated individuals in first generation. In each generation, the fitness of every individual in the population is evaluated, compared with the best value, and modified (recombined and possibly randomly mutated), if required, to form a new population. The new population is then used in the next iteration of the algorithm. The algorithm terminates, when either a maximum number of generations has been produced or a satisfactory fitness level has been reached for the population. The general schema (Figure 8) of GA may be summed up as follows

This study is to determine the set of optimal parameters of friction welding process to ensure minimum weld time, minimum partially deformed zone (Left and Right) and after satisfying the condition of maximum fatigue strength. Mathematical formulation of the problem was carried out to reach the desired output responses. The above constrained optimization problem can mathematically be stated as follows: 
Table 10. Results of ANOVA on desirability analysis.

\begin{tabular}{lcccccc}
\hline \multicolumn{1}{c}{ Factor } & Sum of Squares & $\begin{array}{c}\text { Degree of } \\
\text { freedom }\end{array}$ & Mean squares & FCAL & F-TEST & \% Contribution \\
\hline Speed & 0.60605 & 5 & 0.12121 & 6.73290 & 4.2565 & 37.90 \\
Friction Pressure & 0.41292 & 2 & 0.20646 & 11.4683 & 4.2565 & 25.82 \\
Upsetting Pressure & 0.36128 & 2 & 0.18064 & 10.0339 & 4.2565 & 22.60 \\
Burn-off length & 0.11092 & 2 & 0.05546 & 3.08072 & 4.2565 & 6.94 \\
Error & 0.10802 & 6 & 0.01800 & & & 6.75 \\
Total & 1.59920 & 17 & & & & \\
\hline
\end{tabular}

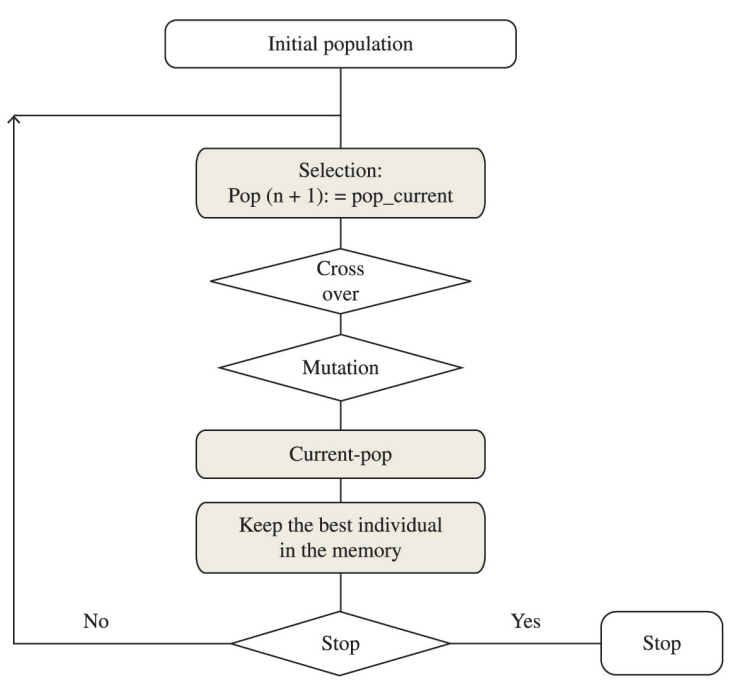

Figure 8. Flow chart representing the GA's principle.

$O f(i)=\frac{c_{f}\left(F_{t}-F_{\exp }\right)^{2}}{F_{t}}+\frac{c_{w}\left(w_{t}-w_{\exp }\right)^{2}}{w_{t}}$

$+\frac{c_{p}\left(P(L)_{t}-P(L)_{\exp }\right)^{2}}{P(L)_{t}}+\frac{c_{p}\left(P(R)_{t}-P(R)_{\exp }\right)^{2}}{P(R)_{t}}$

Where,

- Of(i) - Value of the objective function at the "i" experiment;

- $\mathrm{F}_{\mathrm{t}}$ - Target (desirable) value for fatigue life;

- $\mathrm{F}_{\text {exp }}$ (i) - Experimental value for the fatigue life at the "i" experiment;

- $\mathrm{W}_{\mathrm{t}}$ - Target value for the welding time;

- $\mathrm{W}_{\text {exp }}$ (i) - Experimental value for the welding time at the "i" experiment;

- P(L) - Target value for the left partially deformed zone;

- $\mathrm{P}(\mathrm{L})_{\exp }$ (i) - Experimental value for the left partially deformed zone; at the " $i$ " experiment;

- $\mathrm{P}(\mathrm{R})$ - Target value for the right partially deformed zone;

- $\mathrm{P}(\mathrm{R})_{\exp }$ (i) - Experimental value for the right partially deformed zone at the " $i$ "experiment;

- $\operatorname{cf}(0.6), \mathrm{cw}(0.2)$ and $\mathrm{cp}(0.1)$-Weights that give different status (importance) to each response
Subject to the condition that fatigue life takes the maximum value and welding time and partially deformed zone (left and right) within the range of input parameters.

Regression analysis was carried out using Minitab-14 software using the experimental data collected as per the experiments conducted (Table 3). Output responses were expressed in a coded form as a linear function of process parameters, namely S, FP, UP and BOL, represented by X1, $\mathrm{X} 2 \mathrm{X} 3$ and $\mathrm{X} 4$, respectively.

$$
\begin{aligned}
& F_{\exp } \operatorname{codec}=-129103+37.1(X 1)+563(X 2) \\
& +1600(X 3)+4700(X 4) \\
& W_{\exp } \operatorname{codec}=125+0.0217(X 1)-1.44(X 2) \\
& +0.100(X 3)+0.79(X 4) \\
& P(L)_{\exp }=0.939+0.000003(X 1)-0.00073(X 1) \\
& -0.00253(X 3)+0.0085(X 4) \\
& P(R)_{\exp }=1.20-0.000028(X 1)-0.000810(X 2) \\
& -0.00308(X 3)-0.0025(X 4)
\end{aligned}
$$

The coded and un-coded values of the variables can be related as given below

$$
X 1=\frac{S-(S \max +S \min / 2)}{(S \max -S \min )}
$$

$X 2=\frac{F P-(F P \max +F P \min / 2)}{(F P \max -F P \min )}$

$X 3=\frac{U P-(U P \max +U P \min / 2)}{(U P \max -U P \min )}$

$$
X 4=\frac{B O L-(B O L \max +B O L \min / 2)}{(B O L \max -B O L \min )}
$$

Analysis was carried out at a confidence level of $95 \%$. The un-coded form of the response equations was found to be as follows:

$$
\begin{aligned}
& F_{\text {exp }} \text { un-coded }=-146020+0.0371(S) \\
& +7.04(F P)+32(U P)+1177(B O L) \\
& W_{\exp } \text { un-coded }=125.6+0.0000217(S)-0.018(F P) \\
& +0.002(U P)+0.1975(B O L)
\end{aligned}
$$


$P(L)_{\exp }=0.9375+0.000000003(S)-0.0000092(F P)$

$-0.000050(U P)+0.0021(B O L)$

$P(R)_{\exp }=1.22-0.000000028(S)-0.000010(F P)$

$-0.000062(U P)-0.00063(B O L)$

A binary-coded genetic algorithm (GA) in MATLAB 7.0 was used to solve the optimization problem presented. Inside the experimental space, the GAs chose, randomly, the initial welding setup, i.e., the parameters' values of the first experiment within the input parameter range i.e. Speed (1000-2000rpm), Friction pressure (40-120Mpa), Upsetting pressure (125-175Mpa) and BOL (2-6mm). After it (the first exp.) was done, its response characteristics were measured and fed into the GAs. Then, based on the previous information, the algorithm chose another setup, carried out the experimentation and its data were again fed into the algorithm. This process was continued until the optimum was found, i.e., until the objective function (Equation 15) reached its minimum. In the GA, the population size, crossover rate and mutation rate were important factors in the performance of the algorithm. In this work, the GA parameters selected were as follows, Population size (100), Number of generations (50), Probability of mutation (0.008), Cross over rate $(0.5)$ and Selection function (Roulette).

\section{Results and Discussions}

Investigations were carried out already to assess the relationship of microstructure/property relationships of similar and dissimilar joints of stainless steel by various welding processes ${ }^{18-20}$. Due to the difficulties associated with conventional way of optimization, we used evolutionary computational techniques to get the optimized parameters. Based on the preliminary trails for the grey relational and desirability analysis we identified that the process parameters namely rotational speed, friction pressure, upsetting pressure significantly influenced fatigue life, welding time and partially deformed zone (left\& right) while burn-off-length had relatively small influence. The initial parameters were chosen based on the initial trails and the predicted parameters were selected based on the obtained result from grey relational and desirability analysis. The friction welding was performed on predicted parameters and the fatigue life, welding time, partially deformed zone (left $\&$ right) were measured and compared with the initial set of parameters output values. The predicted values were in good agreement with the initial values for both the models. The least percentage of errors was obtained for initial and predicted parameter output values.

Table 11 reflects the satisfactory results of confirmatory experiment. From Table 11 it is seen that, the predicted input parameters had better fatigue life, lower welding time and partially deformed zone (left \& right). Similarly confirmation test was conducted for the outcomes of desirability analysis. The predicted parameters were found to be better when compared to initial parameters. The validation results demonstrated that the prediction analysis results were quite accurate as the percentages of error in prediction were in a good agreement. The parameters were optimized using binary-coded genetic algorithm (GA) in MATLAB 7.0 software. The properties to be optimized were welding time, partially deformed zone in the left, partially deformed zone in the right and fatigue life. The processed joint was further investigated by microstructure analysis and fracture surface of the fatigue tested sample through SEM analysis. The microstructures of the joint are presented in Figure 9a-c. Figure 9a, shows the well defined grain boundaries and Figure $9 \mathrm{~b}$ it is easily distinguished the weld zone and PDZ. The weld side grains are finer when compared to the PDZ. From Figure 9c, it is observed that the material flow direction from the inner side of the contact surface to the outer boundary.

The fatigue fractured surfaces are analyzed through SEM and its structures are presented in Figure 10a-c.

Table 11. Results of confirmatory experiment (Grey relational).

\begin{tabular}{lcccccccc}
\hline & $\begin{array}{c}\text { Rotational } \\
\text { Speed }\end{array}$ & FP & UP & BOL & Fatigue life & W. time & L-PDZ & R-PDZ \\
\hline Initial parameter & 2000 & 40 & 175 & 4 & 310000 & 209.07 & 0.493 \\
Predicted parameter & 2000 & 40 & 175 & 4 & 312437 & 202.2 & 0.475 & 0.416 \\
Error(\%) & & & & & 0.78 & 3.58 & 3.65 & 3.48 \\
\hline
\end{tabular}

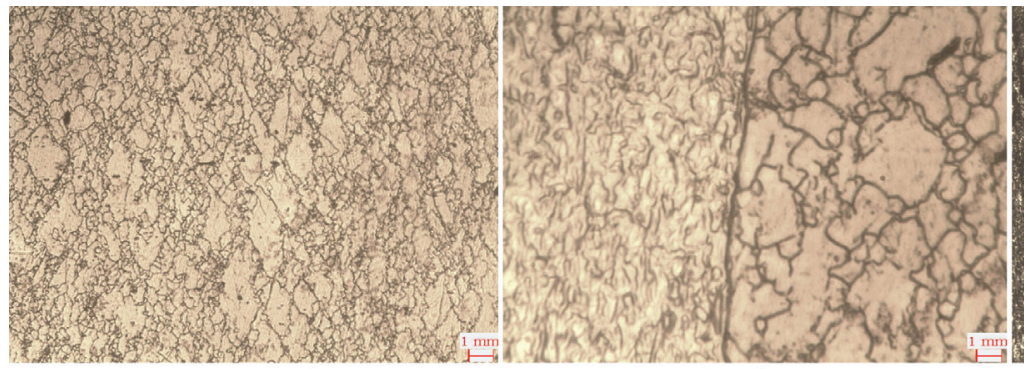

(a) Base metal (b) Weld-PDZ

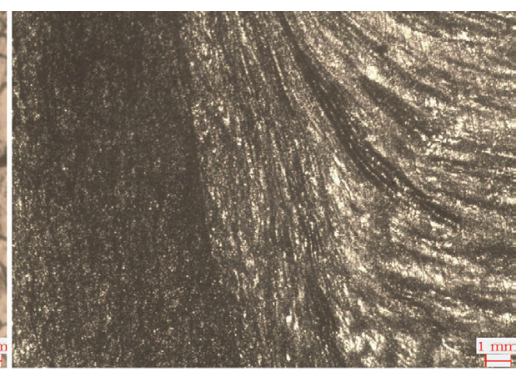

(c) Material flow direction

Figure 9. Different zones of the friction weld microstructures. 


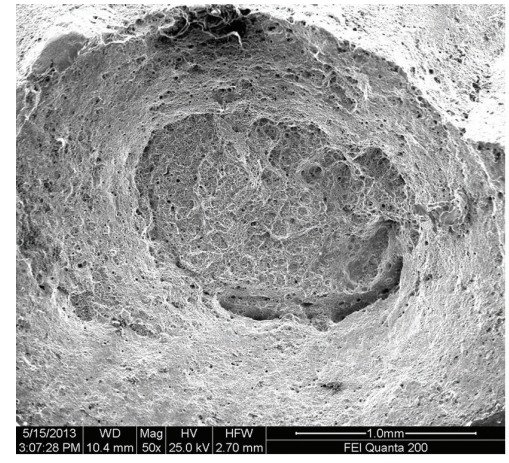

(a)

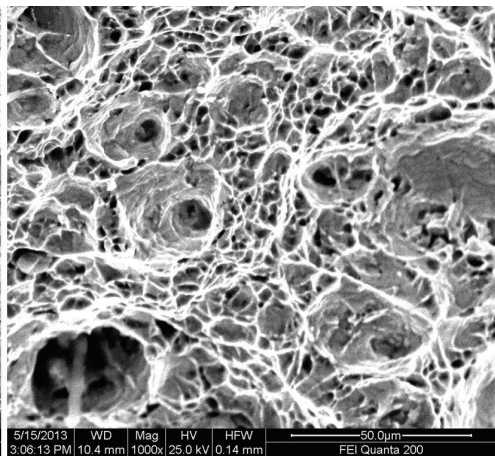

(b)

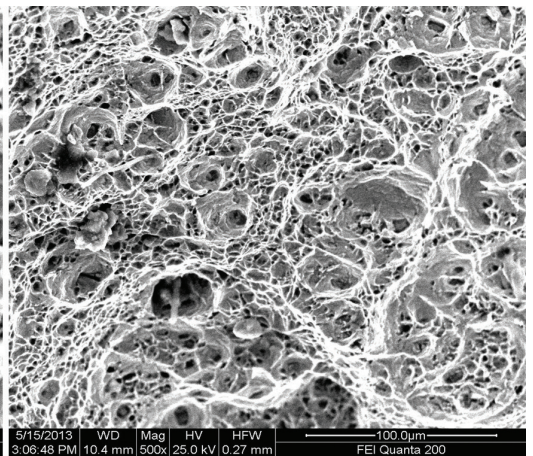

(c)

Figure 10. Fatigue tested fractured surface.

Table 12. Optimum parameter values.

\begin{tabular}{cccc}
\hline Speed $(\mathbf{r p m})$ & Frictional Pressure (MPa) & Upsetting Pressure (MPa) & Burn-off Length (mm) \\
\hline 1998.98 & 119.69 & 174.42 & 5.99 \\
\hline
\end{tabular}

Table 13. Output values corresponding to optimum parameter values.

\begin{tabular}{cccc}
\hline Welding time $(\mathbf{s})$ & L.PDZ $(\mathbf{m m})$ & R.PDZ $(\mathbf{m m})$ & Fatigue life (No of cycles) \\
\hline 47.27 & 0.481 & 0.437 & 310749 \\
\hline
\end{tabular}

From Figure 10a shows the fatigue crack propagated and the nature fracture took place. The fatigue crack fracture exhibits transgranularly under room temperature. From Figure 10b, c, the cleavage-type fractures were observed and also finer dimples are presented.

Since fatigue life was one of the important outputs for determining the life period of the weld, it was given more weightage for optimization of this work. Fatigue life was given a weightage of 0.6 , welding time of 0.2 and the remaining properties such as L.PDZ, R.PDZ of 0.1 each. The optimal values of process parameters obtained by the GA are shown in Table 12.

The near optimum values of speed - $2000 \mathrm{rpm}, \mathrm{FP}-120$ $\mathrm{MPa}, \mathrm{UP}-175 \mathrm{MPa}$ and BOL - $6 \mathrm{~mm}$ were selected for confirmation test. The result of the confirmation test is shown in Table 13.

\section{Conclusions}

The following important conclusions were drawn:

- The optimization of friction welding parameters by grey relational analysis, desirability approach and genetic algorithm was found to be successful;

- Based on ANOVA results, it has been proved that both the grey relational and desirability approach analyses were accurate techniques to optimize the friction welding of super austenitic stainless steel joints;
- Grey relational analysis technique performed better in terms of predicting optimum welding parameters compared to desirability function analysis;

- The optimized values of the parameters by Genetic algorithm were;

- Speed - $1998.98 \mathrm{rpm}$; FP - $119.69 \mathrm{MPa}$; UP - 174.42 MPa; Burn-off Length - 5.99 mm;

- For the optimized parameters, the friction welds were processed and joints exhibited higher fatigue life. There was a good agreement between the theoretically predicted and experimentally obtained values of fatigue life, welding time, L.PDZ and R.PDZ. These computational techniques are the best suited for the optimization of friction welding parameters;

- Cleavage-type fractures were occurred in the fatigue tested samples.

\section{Acknowledgements}

We would like to express and convey our gratitude to Dr. K. Prasad Rao, Professor, Department of Metallurgical and Materials Engineering, for offering us the distinguished opportunity to use the friction welding Machine at the Indian Institute of Technology Madras, Chennai-600 025, TamilNadu, India. 


\section{References}

1. Li W-Y, Yu M, Li J, Zhang G and Wang S. Characterizations of $21-4 \mathrm{~N}$ to $4 \mathrm{Cr} 9 \mathrm{Si} 2$ stainless steel dissimilar joint bonded by electric- resistance-heat-aided friction welding. Journal of Materials and Design. 2009; 30:4230-4235. http://dx.doi. org/10.1016/j.matdes.2009.04.032

2. Sahin M. Evaluation of the joint-interface properties of austenitic-stainless steels (AISI 304) joined by friction welding. Journal of Materials and Design. 2007; 28:2244-2250. http:// dx.doi.org/10.1016/j.matdes.2006.05.031

3. Dey HC, Ashfaq M, Bhaduri AK and Prasad Rao K. Joining of titanium to 304L Stainless steel by friction welding. Journal of Materials Processing Technology. 2009; 209:5862-5870. http:// dx.doi.org/10.1016/j.jmatprotec.2009.06.018

4. Sahin M. Simulation of friction welding using a developed computer program. Journal of Materials Processing Technology. 2004; 153-154:1011-1018. http://dx.doi. org/10.1016/j.jmatprotec.2004.04.287

5. Sathiya P, Abdul Jaleel MY and Katherasan D. Optimization of laser butt welding Parameters with multiple performances characteristic. Journal of optics \& laser Technology. 2011; 43:660-673.

6. Benyounis KY and Olabi AG. Optimization of different welding processes using statistical and numerical approaches. Journal of Advances in Engineering Software. 2008; 39:483496. http://dx.doi.org/10.1016/j.advengsoft.2007.03.012

7. Sathiya P, Aravindan S, Noorul Haq A, Paneerselvam K. Optimization of friction welding parameters using evolutionary computational techniques. Journal of Materials Processing Technology. 2009; 209:2576-2584. http://dx.doi.org/10.1016/j. jmatprotec.2008.06.030

8. Correia DS, Gonçalves CV, Junior SSC and Ferraresi VA. GMAW Welding Optimization Using Genetic Algorithms. Journal of the Brazilian Society of Mechanical Sciences and Engineering. 2004; 26:167-878. http://dx.doi.org/10.1590/ S1678-58782004000100005

9. Dey V, Pratihar DK, Datta GL, Jha MN, Saha TK and Bapat AV. Optimization of bead geometry in electron beam. Journal of Materials Processing Technology. 2009; 209:1151-1157. http://dx.doi.org/10.1016/j.jmatprotec.2008.03.019

10. Paventhan R, Lakshminarayanan PR and Balasubramanian V. Optimization of Friction Welding Process Parameters for Joining Carbon Steel and Stainless Steel. Journal of Iron And
Steel Research International. 2012; 19(1):66-71. http://dx.doi. org/10.1016/S1006-706X(12)60049-1

11. Yousefieh M, Shamanian M and Saatchi A. Optimization of the pulsed current gas tungsten arc welding (PCGTAW) parameters for corrosion resistance of super duplex stainless steel (UNS S32760) welds using the Taguchi method. Journal of Alloys and Compounds. 2010; 509:782-788. http://dx.doi.org/10.1016/j. jallcom.2010.09.087

12. Gunaraj V and Murugan N. Application of response surface methodology for predicting weld bead quality in submerged arc welding of pipes. Journal of Materials Processing Technology. 1999; 88:266-75. http://dx.doi.org/10.1016/ S0924-0136(98)00405-1

13. Rajakumar S, Muralidharan C and Balasubramanian V. Predicting tensile strength, hardness and corrosion rate of friction stir welded AA6061-T6 aluminium alloy joints. Materials \& Design. 2011; 32:2878-2890. http://dx.doi. org/10.1016/j.matdes.2010.12.025

14. Sathiya P, Panneerselvam K and Abdul Jaleel MY. Optimization of laser welding process parameters for super austenitic stainless steel using artificial neural networks and genetic algorithm. Materials \& Design. 2011; 32:1253-1261.

15. Konak A, Coit DW and Smith AE. Multi-objective optimization using genetic algorithms: A tutorial. Reliable Engineering and System Safety. 2006; 91:992-1007. http://dx.doi.org/10.1016/j. ress.2005.11.018

16. Datta S, Bandyopadhyay A and Pal PK. Gery-based taguchi method for optimization of bead geometry in submerged arc bead-on-plate welding. International Journal of Advanced Manufacturing Technology. 2007; 39- 11-12:1136-1143.

17. Deng J. Control problems of grey systems. Systems and control Letter. 1982; 5:288-294.

18. Mohandas T, Madhusudhan Reddy G and Mohammad N. A comparative evaluation of gas tungsten and shielded metal arc welds of a ferritic stainless steel. Journal of Material Processing Technology. 1999; 94:133-140. http://dx.doi. org/10.1016/S0924-0136(99)00092-8

19. Murti KGK and Sundaresan S. Parameter optimization in friction welding dissimilar materials. Metal Construction. 1983; 331-335.

20. Ramazan K and Orhan B. An investigation of microstructure/ properties relationships in dissimilar welds between martensitic and austenitic stainless steel. Materials and Design. 2004; 25:317-329. http://dx.doi.org/10.1016/j. matdes.2003.10.010 